\title{
Bisphosphonates use in a Case of Pachydermoperiostosis
}

\author{
Jagdish RK*, Bhatnagar MK', Malhotra A $^{1}$, \\ Aggarwal $\mathbf{R}^{1}$ and Shailly ${ }^{2}$ \\ ${ }^{1}$ Santosh Medical College \& Hospital, Santosh University, \\ Ghaziabad, India \\ ${ }^{2}$ Chest and TB Hospital, Govt. Medical College, Patiala, \\ India \\ *Corresponding author: Rakesh Kumar J agdish, \\ Department of Rheumatology Clinic, Santosh Medical \\ College \& Hospital, Santosh University, Ghaziabad, India
}

Received: J anuary 05, 2017; Accepted: February 07,

2017; Published: February 09, 2017

\section{Introduction}

Pachydermoperiostosis, also known as Touraine-Solente-Gole' syndrome, primary or idiopathic Hypertrophic Osteoarthropathy (HOAP). It is a rare autosomal disorder with variable expression. Pachydermoperiostosis is characterized by bilateral and symmetrical grade IV clubbing, periosteal new bone formation, thickening of skin (pachyderma) and excessive sweating (hyperhydrosis). No treatment is curative, symptomatic treatment such as NSAIDS, Steroids, colchicines are used. There are case reports of bisphosphonates use with good results in secondary HOAP $[1,2]$. The uses of bisphosphonates in primary HOAP/Pachydermoperiostosis are only few [3].

\section{Case Presentation}

A 31 years old, male patient, non smoker, non alcoholic, resident of Bihar, presented to us with history of pain and swelling in hands and feet, followed by involvement of ankle, knee and wrist joints, of 15 years duration, this was associated with hyperhydrosis of palms and soles. There was no history of fever, palpitation, bluish discolouration, backache, haemoptysis, haemetemesis, hematuria, haematochezia, cough, expectorations, dyspnea, oral ulcers, weight loss and bleeding tendency. Family history of similar complains positive in paternal cousin brother.

On physical Examination, He was a febrile, Pulse-70/min, Respiratory rate-16/min, $\mathrm{BP}-122 / 80 \mathrm{mmHg}, \mathrm{SpO} 2-98 \%$ at room air, there was no cyanosis, pallor, lymphadenopathy and oedema. On systemic examination-respiratory, cardiovascular, abdominal and neurological examination were normal, on skin examination there was furrowing on the forehead, skin is oily and shiny in appearance (Figure 1), Hyperhydrosis of hands and feet. Musculoskeletal examination shows-grade IV clubbing along with widening of wrist and ankle joint, swelling of both the knee joint (Figures 3-6).

On investigation his haemoglobin, ESR, CRP, leukocyte count and platelet count were within normal limits. Peripheral blood film showed normocytic norm chromic picture. Liver function test, kidney function test and thyroid function test were normal. Blood sugar was within normal range. Urine examination was also within normal range. Stool for occult blood, chest X-ray PA view, Contrast enhanced CT chest [2], Dechocardiography, USG abdomen and pelvis were normal. Other radiological investigations, X- ray of ulna, radius, tibia and fibula showed wavy periosteal reaction along the distal meta-diaphyses (Figure 2). On the basis of history, physical examination and investigations we made diagnosis of Primary HOAP (Pachydermoperiostosis).

His main problem was of bony pains and swelling, We started him on NSAID, steroids, colchicines, added one after the other to relive pain over six months without much relief, we gave bisphosphonates infusion (pamidronic acid ) $60 \mathrm{mg}$ over 2 hours slowly, after hydration with $500 \mathrm{ml}$ normal saline, patient responded well in the form of pain relief in 3-4 days of treatment and decrease in swellings of hand, feet and knee in 7-10 days, patient was better for 3 months of follow up but again same symptoms and signs repaper then a long acting bisphosphonates zolendronic acid $4 \mathrm{mg}$ given with prior hydration which resulted in marked improvement as shown in images and it is persisting till date after 6 months of infusion during follow up. Oral glycopyrolate was given for hyperhydrosis with good result.

Images comparison before bisphosphonates treatment and after bisphosphonates treatment given below (Figures 3-6).

\section{Discussion}

Primary HOAP/Pachydermoperiostosis is an autosomal dominant disease with incomplete penetrance and variable expression, in few cases autosomal recessive and $\mathrm{X}$-linked inheritance can be there [1] and family history present in $1 / 3^{\text {rd }}$ of cases only. The disease begins insidiously at puberty and nine times more common in males. Symptoms usually disappear at adulthood but in our patient symptoms persisted and patient did not respond to usual treatment.

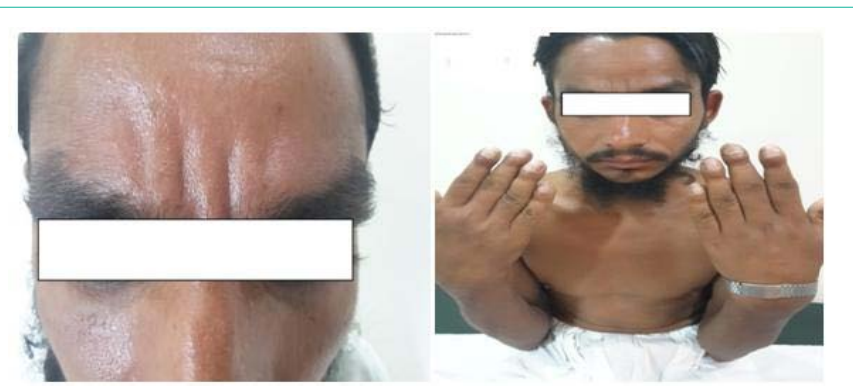

Figure 1: Facial features-furrowing on the forehead with oily and shiny skin.
Austin J Orthopade \& Rheumatol - Volume 4 Issue 1 - 2017 ISSN: 2472-369X | www.austinpublishinggroup.com Jagdish et al. (c) All rights are reserved
Citation: Jagdish RK, Bhatnagar MK, Malhotra A, Aggarwal R and Shailly. Bisphosphonates use in a Case of Pachydermoperiostosis. Austin J Orthopade \& Rheumatol. 2017; 4(1): 1046. 


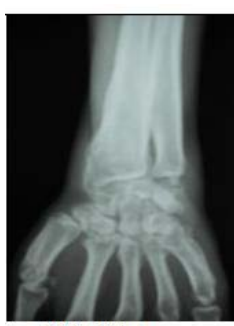

Wrist Joint

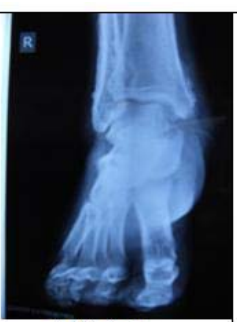

Ankle joint

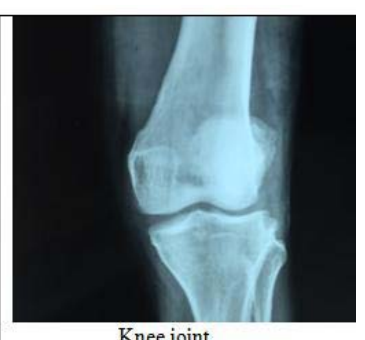

Knee joint
Figure 2: Periosteal reaction-wavy periosteal reaction along the distal metadiaphyses of ulna, radius, tibia and fibula and around knee joint.

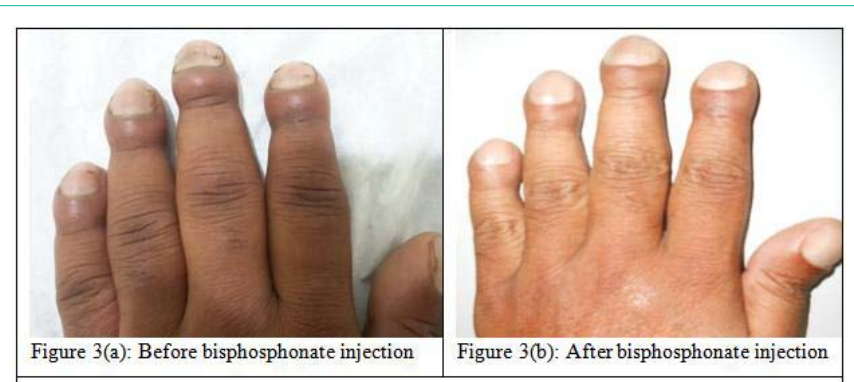

Figure 3: Hands-soft tissue swelling significantly reduced post treatment.

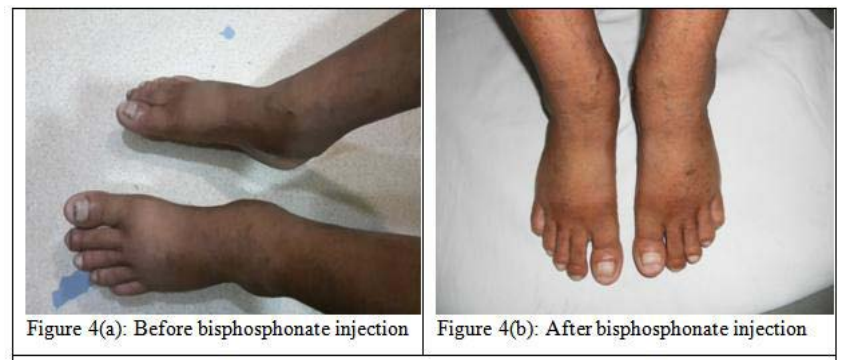

Figure 4: Feet and ankle swelling reduced significantly post treatment.

Exact pathology is unclear but it is suggested that abnormal production of growth factors [2] like VEGF (Vascular Endothelial Growth Factor) and PDGF (Platelet Derived Growth Factor) are playing central role. It is a rare disease and should be differentiated from other causes of clubbing like chronic suppurative pulmonary diseases, bronchogenic carcinoma and lung metastases, cystic fibrosis and cyanotic congenital malformations of the heart, thyroid acropachy, acromegaly and chronic inflammatory rheumatic diseases [2]. Long term prognosis of Pachydermoperiostosis is generally non fatal. No treatment is curative. Various symptomatic treatment strategies are there for Pachydermoperiostosis, including NSAIDS, Steroids, colchicine, vagotomy for skeletal symptoms, botulinium toxin type A, Isotretinoin [4] and plastic surgery for dermatological manifestation, Beta blockers, glycopyrolate or neurotoxins for hyperhydrosis, Newer therapies [2] are emerging like octreotide, gefetinib (EGFR inhibiotor), bisphoshphonates (pamidronate or zoledronate) [2,3]. Bishphosphonates exert their therapeutic effects though potent inhibition of osteoclastic bone resorption. They also have anti-inflammatory, antiangiogenic effects and also reduce vascular endothelial growth factor [7]. Bisphosphonates [3] had also been tried in painful bony conditions in Rheumatoid Arthritis

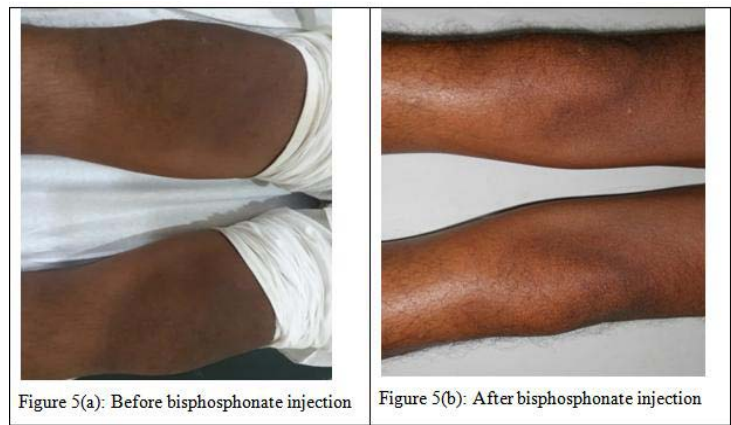

Figure 5: Knee Effusion-decreased significantly post treatment.

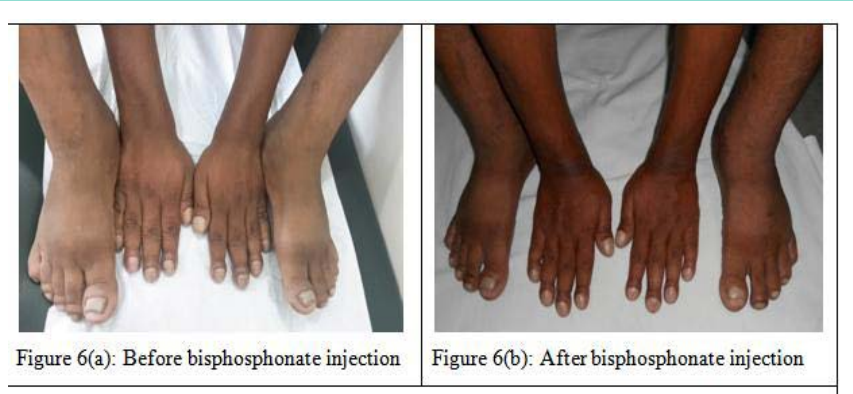

Figure 6: Hands, Wrist, Feet and Ankle swelling significantly reduced post treatment.

(RA), Spondyloarthritis (SpA) $[2,4,5]$ bony metastasis, bone pain in secondary HOAP [6,7], multiple myeloma.

We have earlier experience of using injectable bisphosphonates in painful Ankylosing Spondylitis (AS) patients. In primary HOAP3, there is few case report of use of bisphosphonates therapy with good result. We tried bisphosphonates in its treatment with encouraging results, with maximal effect on pain followed by effusions and no effect on bone deformities and clubbing. We suggest that injectable bisphosphonates should be tried early in pachydermoperiostosis. Consistent effect was seen with long acting zolendronic acid than pamidronic acid.

\section{References}

1. Castori M, Sinibaldi L, Mingarelli R, Lachman RS, Rimoin DL, Dallapiccola B. Pachydermoperiostosis: an update. Clin Genet. 2005; 68: 477-486.

2. Bernardo SG, Emer JJ, Burnett ME, Gordon M. Hypertrophic osteoarthropathy presenting as unilateral cellulitis with successful treatment using pamidronate disodium. J Clin Aesthet Dermatol. 2012; 5: 37-46.

3. Karunasree $N$ \& Narasimha rao R. Management of Pachydermoperiostosis with Bisphosphonates, Isotretinoin and Colchicine-A Case Report. International Journal of Pharmacy and Biological Sciences. 2015; 5: 18-23.

4. Santra G, Sarkar RN, Phaujdar S, Banerjee S, Siddhanta S. Assessment of the efficacy of pamidronate in ankylosing spondylitis: an open prospective trial. Singapore Med J. 2010; 51: 883-887.

5. Amital H, Applbaum YH, Vasiliev L, Rubinow A. Hypertrophic pulmonary osteoarthropathy: control of pain and symptoms with pamidronate. Clin Rheumatol. 2004; 23: 330-332.

6. King MM, Nelson DA. Hypertrophic osteoarthropathy effectively treated with zoledronic acid. Clin Lung Cancer. 2008; 9: 179-182.

7. Wood J, Bonjean K, Ruetz S, Bellahcène A, Devy L, Foidart JM, et al. Noval antiangiogenic effects of bisphosphonates compound zolendronicacid. J Pharmacol Exp Ther. 2002; 302: 1055-1061. 